\title{
Effect of Monosodium Glutamate on Behavioral Phenotypes, Biomarkers of Oxidative Stress in Brain Tissues and Liver Enzymes in Mice
}

\author{
Solomon Umukoro1*, Gabriel Oluwafemi Oluwole1, Henry Egbewunmi Olamijowon1, \\ Adrian Itiviere Omogbiya², Anthony Taghogho Eduviere ${ }^{3}$ \\ ${ }^{1}$ Department of Pharmacology and Therapeutics, College of Medicine, University of Ibadan, Ibadan, Nigeria \\ ${ }^{2}$ Department of Pharmacology and Therapeutics, College of Health Sciences, Delta State University, \\ Abraka, Nigeria \\ ${ }^{3}$ Department of Pharmacology and Therapeutics, College of Medicine and Health Sciences, \\ Afe Babalola University, Ado-Ekiti, Nigeria \\ Email:*umusolo@yahoo.com
}

Received 29 August 2015; accepted 2 November 2015; published 6 November 2015

Copyright (C) 2015 by authors and Scientific Research Publishing Inc.

This work is licensed under the Creative Commons Attribution International License (CC BY).

http://creativecommons.org/licenses/by/4.0/

(c) (i)

Open Access

\section{Abstract}

The effects of oral administration of low doses of monosodium glutamate (MSG) on behavioral phenotypes, biomarkers of oxidative stress in the brain and liver enzymes in mice were evaluated in this study. Mice were treated orally with MSG $(100,250$ and $500 \mathrm{mg} / \mathrm{kg})$ daily for 21 days before testing for behavioral phenotypes; memory, anxiety, spontaneous motor activity (SMA) and depression. Thereafter, the brain levels of malondialdehyde (MDA) and glutathione (GSH) as well as the activities of liver enzymes, aminotransferase (AST) and alanine aminotransferase (ALT) were determined spectrophotometrically. MSG did not produce significant $(P>0.05)$ impairment of memory in the Y-maze test. It also failed to modify the behaviors of mice in the elevated plus maze and light/dark transition tests of animal models of anxiety. MSG had no significant effect on SMA but produced depressive-like symptoms in the forced swim test at a dose of $500 \mathrm{mg} / \mathrm{kg}$. Moreover, it increased the levels of MDA and decreased GSH concentrations in brain tissues of mice. The activity of AST and ALT were elevated in the blood of MSG-treated mice suggesting liver injury. Taken together, these findings suggested that MSG induced oxidative stress in the brain and impaired liver functions but did not produce any behavioral abnormalities in mice at lower doses.

*Corresponding author.

How to cite this paper: Umukoro, S., Oluwole, G.O., Olamijowon, H.E., Omogbiya, A.I. and Eduviere, A.T. (2015) Effect of Monosodium Glutamate on Behavioral Phenotypes, Biomarkers of Oxidative Stress in Brain Tissues and Liver Enzymes in Mice. World Journal of Neuroscience, 5, 339-349. http://dx.doi.org/10.4236/wjns.2015.55033 
Keywords

Monosodium Glutamate, Depression, Oxidative stress, Liver Enzymes

\section{Introduction}

Monosodium glutamate (MSG) commonly known as Aji-nomoto, is the sodium salt of glutamic acid [1]. Glutamate is one of the most abundant naturally occurring amino acids found in most foods such as dairy products, meat, fish and many vegetables such as mushrooms and tomatoes [2]. MSG is well-known as food additive, and is widely used across the globe to enhance the taste and flavor of a variety of food preparations including many processed foods and snacks. Despite its widespread use as food flavor, there are reports which indicate that MSG is toxic to humans and laboratory animals especially at high doses [3]. Also, MSG has been alleged to cause asthma, urticaria, atopic dermatitis, ventricular arrhythmia, neuropathy and abdominal discomfort [4]. It has also been implicated in male infertility by causing testicular damage and abnormal sperm cell morphology [2]. Moreover, it has been reported that MSG is neurotoxic, capable of producing degeneration of population of neurons, accompanied by pathological conditions, such as stroke, epilepsy, schizophrenia, anxiety, depression, Parkinson's disease, Alzheimer's disease, Huntington's disease, and amyotrophic lateral sclerosis [2] [5]. This could be due to its well known excitotoxic effect, as MSG can overexcite neuronal cells to the point of damage or death, resulting in brain injury, mostly accompanied by oxidative stress [5] [6]. However, the role of MSG in these neuropsychiatric disorders still remains vague and warrants further investigations.

Although the effects of MSG have been extensively studied for over a century, it will still continue to be evaluated for safety profiles in light of current scientific knowledge and methods of testing [2] [7]. Dietary intake of MSG in United Kingdom has been estimated to be about 4 grams per week, which is comparable to U.S. estimates of roughly 0.55 grams for the average consumers, spread out over the period of the day [2]. Previous studies revealed that MSG was neurotoxic and produced seizures, memory deficits, anxiety and other neurological disorders in rodents [5] [6] [8]-[11]. However, the doses used in these studies were too high and far above the possible amount consumed by humans. Moreover, MSG in some of these studies was mixed with the animal food, which further compromised the result outcomes, as it was difficult to ascertain the amount consumed by the animals [2]. The route of administration also influences the toxicity profiles of MSG, especially as the human body is known to effectively metabolize added glutamate in the same manner as it metabolizes glutamate found in many foods [5] [8]-[11]. Thus, the use of route that bypasses the gastrointestinal tract will jeopardize the extrapolation of animal data to humans [12].

The liver is the major organ involved in the metabolism of MSG, thus making it more vulnerable to the toxic effect of this commonly consumed food additive. Previous studies have confirmed that MSG is toxic to the liver cells through generation of excess ammonium ions and reactive oxygen species [1] [3] [13]. The ammonium ion overload is known to trigger the formation of reactive oxygen species, which react with polyunsaturated fatty acids of cell membrane leading to impairment of mitochondrial and plasma membranes accompanied by leakage of liver enzymes such as ALT and AST [14]. Elevation of serum ALT and AST levels are used routinely as biomarkers of liver injury [15]. Moreover, previous studies have shown that MSG impaired liver function and elevated serum ALT and AST levels in rats [1] [3] [13] [15]. However, it is worthy to note that liver impairment will lead to increased blood level of MSG, which may further enhance its neurotoxic effects. This study is therefore designed to examine the effects of oral administration of MSG on behavioral phenotypes, biomarkers of oxidative stress and liver enzymes in mice at lower doses.

\section{Materials and Methods}

\subsection{Experimental Animals}

Male Swiss mice (20 - 22 g, 7 weeks old) used in the study were obtained from the Central Animal House, University of Ibadan. The animals were housed in plastic cages at room temperature and normal relative humidity, and they had free access to commercial food pellets and water ad libitum. The animals were acclimatized for one week and were kept under $12 \mathrm{hr}$ light/dark cycles throughout the experiments. The experimental procedures were carried out in compliance with National Institutes of Health Guide for Care and Use of Laboratory Animals. 


\subsection{Drugs and Chemicals}

Commercial MSG (West African Seasoning Co. Ltd. Lagos, Nigeria), trichloroacetic acid-TCA (Burgoyne Burbidges \& Co., Mumbai, India), thiobarbituric acid-TBA (Guangdong Guanghua Chemical Factory Co., Ltd), 5, 5'-dithio-bis (2-nitrobenzoic acid)-DTNB (Aldrich, Germany) and tris (hydroxymethyl)-amino-methane (Trisbuffer) (Hopkin \& Williams Company, USA) were used in the study.

\subsection{Drug Preparation}

MSG was dissolved in distilled water immediately before use and the doses of 100, 250 and $500 \mathrm{mg} / \mathrm{kg}$ of MSG used in this study were chosen based on information obtained from previous reports [2] [16].

\subsection{Behavioral Assessment}

Male Swiss mice were randomly distributed into various treatment groups $(\mathrm{n}=5)$ and were treated orally with MSG (100, 250 and $500 \mathrm{mg} / \mathrm{kg})$ or distilled water $(10 \mathrm{ml} / \mathrm{kg})$ daily for 21 days before testing for behavioral phenotypes; memory, anxiety, SMA and depression. Each of the apparatus used for the behavioral tests was cleaned with $10 \%$ ethanol before the first test and also in between tests.

\subsubsection{Performance of Mice in Y-Maze Task}

The Y-maze test was used to assess the effect of MSG on working memory in mice [17]. Mice were placed individually in the Y-maze and allowed to explore all the three arms freely for 5 min period. Mice were placed in the Y-maze $30 \mathrm{~min}$ after the last treatment. The parameters assessed were number of arm entries and alternations. An entry was scored when the four paws of the animals were completely in the arm of the Y-maze. The percentage alternation, which indicated memory performance, was calculated by dividing the total number of alternations by the total number of arm entries, minus two and multiplied by 100 [17].

\subsubsection{Behavior of Mice in the Elevated Plus Maze (EPM) Test}

The EPM test was used to assess the level of anxiety-like behavior in mice according to the method previously described [18]. Mice were placed individually in the centre square facing an open arm of the EPM immediately after each test of the Y-maze task and were allowed to explore the maze for a period of $5 \mathrm{~min}$. The parameters measured were the total time spent in the open and closed arms as well as the frequency of transitions into the open and closed arms of the EPM.

\subsubsection{Behavior of Mice in the Light/Dark Transition Test}

The light/dark transition test was further used to evaluate the effect of MSG on anxiety-like behavior in mice [19]. Mice were placed individually in the light/dark box immediately after completion of each test of the EPM maze task. Thereafter, the number of entries and time spent in the light and dark compartments of the box were measured for a period of 5 min.

\subsubsection{Performance of Mice in the Open Field Test}

The open field test was used to assess the effect of MSG on SMA according the method previously described [20]. Mice were placed in the center of the open field arena immediately after the light/dark transition test. Then, the number of line crossed and duration of ambulation were measured for a period of 5 min.

\subsubsection{Behavior of Mice in the Forced Swim Test (FST)}

The forced swim test was employed to assess the effect of MSG on behavioral depression according to the method previously described by Porsolt et al. [21]. Mice were forced to swim individually for 6 min in a glass jar of height $20 \mathrm{~cm}$, diameter $10 \mathrm{~cm}$ and filled with fresh water at room temperature to a depth of $15 \mathrm{~cm}$. The FST was carried out immediately after completion of each test of the open field paradigm. The parameters measured were first occurrence of immobility (the period the animal swims continuously before the first pause of swimming activity), duration of immobility (the total time during which the animal is immobile) and total time spent in active swimming (the total duration during which the animal swims throughout the experimental period). 


\subsection{Biochemical Assays}

After testing for behavioral functions, the animals were decapitated under ether anesthesia and the brains were immediately removed and kept in the refrigerator for $30 \mathrm{~min}$. Thereafter, the whole brain was weighed and homogenized with $10 \%$ w/v sodium phosphate buffer (0.1 M, pH 7.4).

\subsubsection{Estimation of Brain Glutathione Concentration}

Aliquots of brain tissue homogenates of individual mouse in the respective treatment groups were taken and the concentration of reduced GSH, which serves as a measure of oxidative stress, was determined using the method of Moron et al. [22]. Equal volume $(0.4 \mathrm{ml})$ of brain homogenate and 20\% TCA (0.4 ml) were mixed and then centrifuged using a cold centrifuge at $10,000 \mathrm{rpm}$ at $4^{\circ} \mathrm{C}$ for $20 \mathrm{~min}$. The supernatant $(0.25 \mathrm{ml})$ was added to 2 $\mathrm{ml}$ of $0.6 \mathrm{mM}$ DTNB and the final volume was made up to $3 \mathrm{ml}$ with sodium phosphate buffer $(0.2 \mathrm{M}, \mathrm{pH} 8.0)$. The absorbance was then read at $412 \mathrm{~nm}$ against blank reagent using a spectrophotometer. The concentrations of GSH in the brain tissues were expressed as micromoles per gram tissue ( $\mu \mathrm{mol} / \mathrm{g}$ tissue).

\subsubsection{Estimation of Brain Level of Malondialdehyde}

The brain level of MDA, a major biomarker of lipid peroxidation, was estimated according to the method of Adam-Vizi and Seregi [23]. An aliquot of $0.4 \mathrm{ml}$ of the sample was mixed with $1.6 \mathrm{ml}$ of Tris-KCl buffer (pH 7.4) to which $0.5 \mathrm{ml}$ of $30 \%$ TCA was added. Then, $0.5 \mathrm{ml}$ of $0.75 \%$ TBA was added and placed in a water bath for 45 minutes at $80^{\circ} \mathrm{C}$. This was then cooled in ice and centrifuged at $3000 \mathrm{rpm}$ for 15 minutes. The clear supernatant was collected and absorbance measured against a reference blank of distilled water at $532 \mathrm{~nm}$ using a spectrophotometer. The MDA concentration was calculated using a molar extinction coefficient of $1.56 \times 105$ $\mathrm{M}^{-1} \cdot \mathrm{cm}^{-1}$ and values were expressed as $\mu$ moles of MDA per gram tissue.

\subsection{Assessment of Liver Function Enzymes in the Blood}

Alanine aminotransferase (ALT) and aspartate aminotransferase (AST) activities in serum were determined spectrophotometrically. Another set of mice ( $\mathrm{n}=5$ per group) received MSG (100, 250 and $500 \mathrm{mg} / \mathrm{kg}$ ) or distilled water $(10 \mathrm{ml} / \mathrm{kg})$ daily for 21 days. Thirty minutes after the last treatment, blood was collected from each animal through ocular puncture and centrifuged at $10000 \mathrm{rpm}$ for 15 min using cold centrifuge. Serum was collected separately and $0.1 \mathrm{ml}$ of each sample was mixed with sodium phosphate buffer $(100 \mathrm{mmol} / \mathrm{L}, \mathrm{pH} 7.4)$, L-aspartate $(100 \mathrm{mmol} / \mathrm{L})$, and $\alpha$-oxoglutarate $(2 \mathrm{mmol} / \mathrm{L})$. Thereafter, the mixture was incubated for exactly 30 $\min$ at $37^{\circ} \mathrm{C}$. Then, $0.5 \mathrm{ml}$ of 2,4 dinitrophenylhydrazine $(2 \mathrm{mmol} / \mathrm{L})$ was added to the reaction mixture and allowed to stand for exactly $20 \mathrm{~min}$ at $25^{\circ} \mathrm{C}$. Thereafter, $5.0 \mathrm{ml}$ of sodium hydroxide $(0.4 \mathrm{~mol} / \mathrm{L})$ was added and the absorbance was read against the reagent blank after 5 min at $546 \mathrm{~nm}$ [24].

\subsection{Statistical Analysis}

Data were analyzed using Graph Pad Prism software version 4.0 and expressed as mean \pm S.E.M. Statistical analysis was done using one-way ANOVA, followed by Newman-Keuls post-hoc test. $P$ values $<0.05$ were considered statistically significant.

\section{Results}

\subsection{Effect of Monosodium Glutamate on Memory Performance}

The effect of MSG on working memory as assessed by the alterations in alternation behavior of mice in the Y maze paradigm is shown in Figure 1. One-way ANOVA showed that there no were significant differences between treatment groups: $[\mathrm{F}(3,16)=1.078 ; P=0.3866]$. Moreover, MSG $(100,250 \mathrm{or} 500 \mathrm{mg} / \mathrm{kg}$, p.o) given daily for 21 days did not produce memory impairment, as it failed to significantly $(P=0.3866)$ alter the alternation behavior in comparison with control (Figure 1).

\subsection{Effects of Monosodium Glutamate on Anxiety}

The effects of MSG on anxiety as assessed by the EPM test are shown in Figure 2(a) and Figure 2(b). One-way ANOVA revealed that there were no significant differences between treatment groups: open arm entry $[\mathrm{F}(3,16)$ 


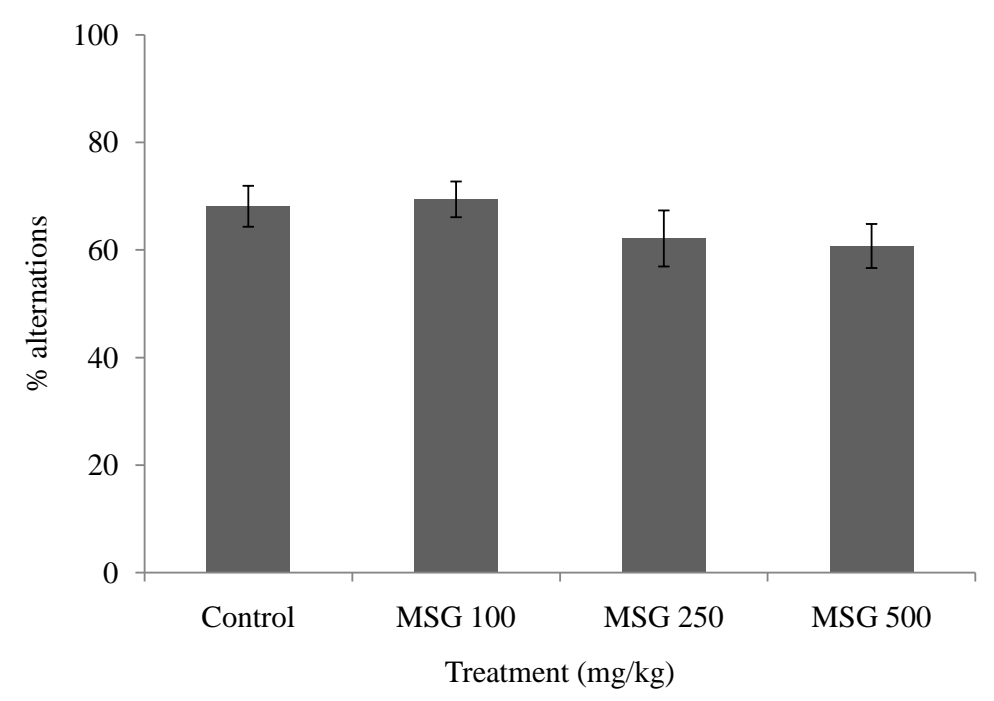

Figure 1. Effect of monosodium glutamate on percentage alternations in the $\mathrm{Y}$-maze. Values represent the Mean \pm S.E.M for 5 animals per group. $P>0.05$ compared with control.

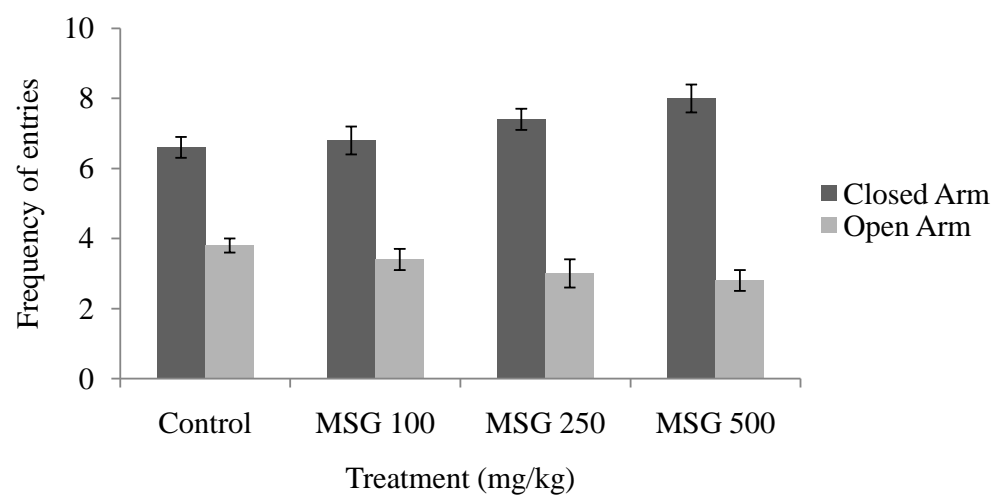

(a)

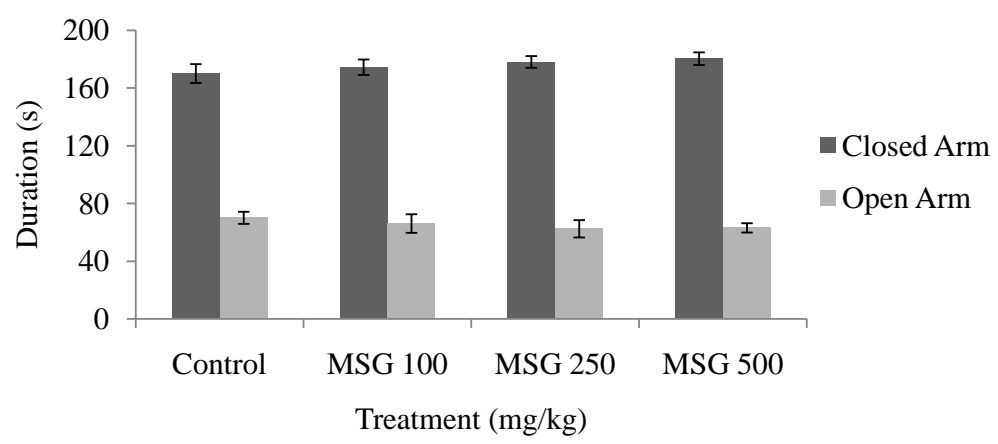

(b)

Figure 2. Effects of monosodium glutamate on the frequency of entries (a) and duration of stay (b) the arms of the elevated plus maze. Each column represents the Mean \pm S.E.M for 5 animals per group. $P>0.05$ compared with control.

$=0.3224, P=0.8091]$; closed arm entry $[\mathrm{F}(3,16)=0.7767, P=0.8091]$; duration of time spent in open arm $[\mathrm{F}$ $(3,16)=0.4590, P=0.7147]$ and duration of time spent in closed arm $[\mathrm{F}(3,16)=0.7620, P=0.5317]$. Furthermore, MSG did not significantly $(P>0.05)$ modifies the behavior of mice in the EPM test when compared with control (Figure 2(a) and Figure 2(b)). In addition, the effect of MSG on the performance of mice in the 
light/dark transition test, as measured by the amount of time spent in the light and dark compartments are shown in Figure 3. One-way ANOVA showed that there were no significant differences between treatment groups: time spent in light compartment $[\mathrm{F}(3,16)=0.3368, P=0.7990]$ and time spent in dark compartment $[\mathrm{F}(3,16)$ $=0.6455, P=0.5970]$. Thus, MSG did not significantly $(P>0.05)$ alter the performance of mice in the light/dark transition test, as measured by the amount of time spent in the light and dark compartments of the light/dark box (Figure 3).

\subsection{Effect of Monosodium Glutamate on Spontaneous Motor Activity}

The effect of MSG on SMA which was assessed by the number of line crossed and duration of ambulation in the open field test are presented in Table 1. One-way ANOVA revealed that there were no significant differences between treatment groups: number of line crossed $[\mathrm{F}(3,16)=0.4413, P=0.7266]$ and duration of ambulation $[\mathrm{F}(3,16)=0.6358, P=0.6028]$. Oral administration of MSG $(100-500 \mathrm{mg} / \mathrm{kg}, \mathrm{p} . \mathrm{o})$ daily for 21 days did not produce significant alteration in the number of line crossed $(P=0.727)$ and duration of ambulation $(P=0.603)$ in mice when compared with control (Table 1).

\subsection{Effect of Monosodium Glutamate on Performance of Mice in Forced Swim Test}

Table 2 showed the effects of oral administration of MSG on performance of mice in the forced swim test. One-

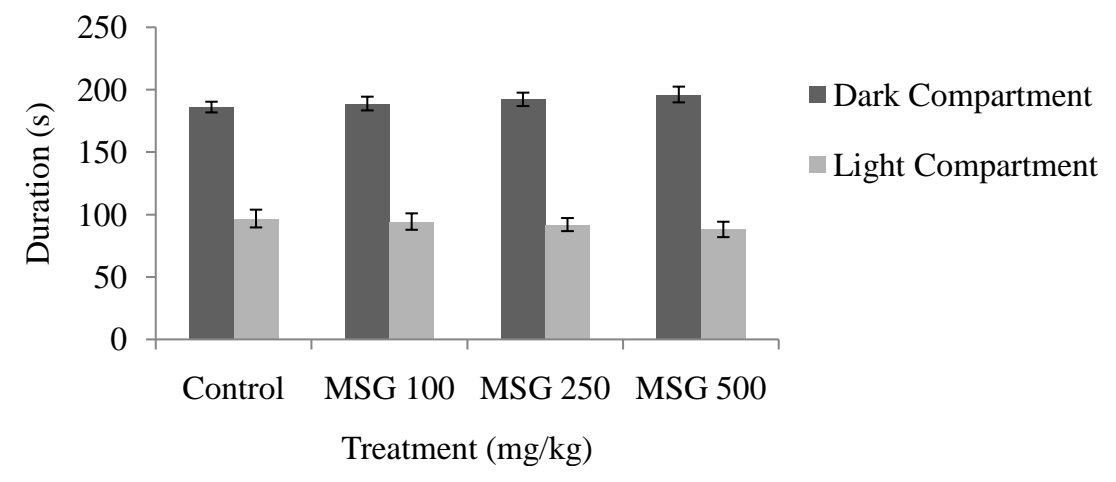

Figure 3. Effect of MSG on time spent in the dark and light compartments. The values represent the Mean \pm S.E.M for 5 animals per group. $P>0.05$ compared with control group.

Table 1. Effect of monosodium glutamate on spontaneous motor activity in mice.

\begin{tabular}{cccc}
\hline Treatment Group & Dose $(\mathrm{mg} / \mathrm{kg})$ & Number of line crossed & Duration of ambulation (s) \\
\hline Control & - & $74.40 \pm 3.88$ & $81.00 \pm 3.59$ \\
MSG & 100 & $75.20 \pm 3.68$ & $84.20 \pm 4.53$ \\
MSG & 250 & $77.80 \pm 4.50$ & $86.40 \pm 3.47$ \\
MSG & 500 & $80.60 \pm 4.74$ & $88.00 \pm 3.51$ \\
\hline
\end{tabular}

Values represent the Mean \pm S.E.M for 5 animals per group. $P>0.05$ compared with control.

Table 2. Effect of monosodium glutamate on performance of mice in the forced swim test.

\begin{tabular}{ccccc}
\hline Treatment Group & Dose $(\mathrm{mg} / \mathrm{kg})$ & Latency to Immobility (s) & Total Swimming time (s) & Duration of Immobility (s) \\
\hline Control & - & $38.00 \pm 3.39$ & $126.20 \pm 5.12$ & $142.40 \pm 6.07$ \\
MSG & 100 & $42.20 \pm 2.13$ & $129.40 \pm 3.14$ & $138.00 \pm 5.36$ \\
MSG & 250 & $40.40 \pm 3.27$ & $120.40 \pm 3.39$ & $148.20 \pm 4.21$ \\
MSG & 500 & $35.20 \pm 4.01$ & $110.20 \pm 4.24^{*}$ & $170.00 \pm 4.55^{*}$ \\
\hline
\end{tabular}

Values represent the Mean \pm S.E.M for 5 animals per group. ${ }^{*} P<0.05$ compared with control. 
way ANOVA revealed that there were no significant differences between treatment groups: latency to immobility $[\mathrm{F}(3,16)=0.8620, P=0.4809]$. Moreover, MSG $(500 \mathrm{mg} / \mathrm{kg})$ given daily for 21 days did not significantly prolong the latency to immobility $(P=0.4809)$. However, MSG at a dose of $500 \mathrm{mg} / \mathrm{kg}$, significantly increased the duration of immobility $(P=0.020)$ and also reduced the total time spent in active swimming $(P=0.0240)$ when compared with control, which suggests depressive-like effect (Table 2).

\subsection{Effect of Monosodium Glutamate Produces Increase in Oxidative Stress in Mouse Brain}

The effects of MSG on MDA and GSH, the major biomarkers of oxidative stress are shown in Table 3. Oneway ANOVA revealed that there were significant differences between treatment groups; $\operatorname{MDA}[\mathrm{F}(3,16)=$ 8.628, $P=0.0012]$ and GSH $[\mathrm{F}(3,16)=8.116, P=0.0016]$. Post-hoc analysis by Newman Keuls test showed that MSG $(250$ and $500 \mathrm{mg} / \mathrm{kg})$ significantly elevated MDA level $(P=0.0012)$ but decreased GSH content $(P=$ 0.0016 ) in the brain tissue of mice suggesting increased oxidative stress (Table 3 ).

\subsection{Effects of Monosodium Glutamate on Liver Enzymes}

The activities of AST and ALT enzymes in the blood obtained from MSG-treated mice are shown in Figure 4(a) and Figure 4(b). One-way ANOVA revealed that there were significant differences between treatment groups: AST $[F(3,16)=46.6, P=0.001]$ and $\operatorname{ALT}[F(3,16)=9.754, P=0.002]$. Post hoc analysis by Newman Keuls test showed that MSG (100, 250 and $500 \mathrm{mg} / \mathrm{kg}$ ) given orally for 21 days produced a significant elevation of liver function enzymes; AST $(P=0.001)$ and ALT $(P=0.002)$ in comparison with control suggesting liver injury (Figure 4(a) and Figure 4(b)).

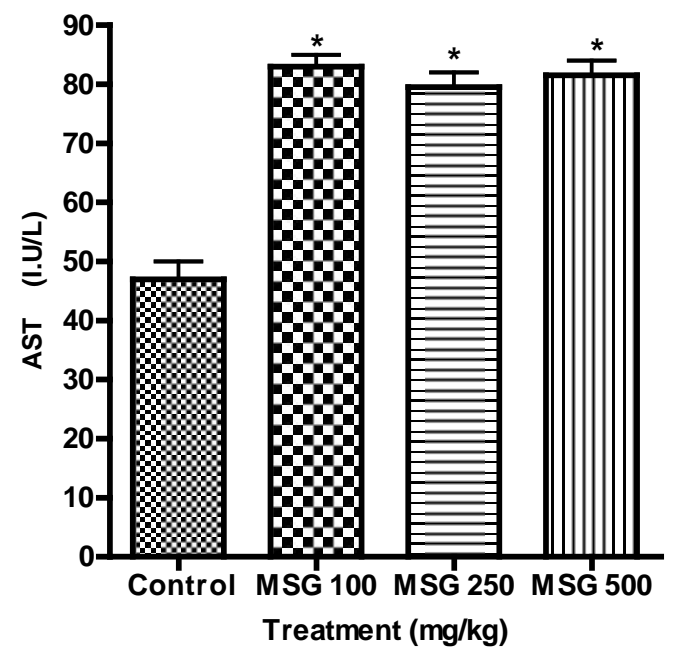

(a)

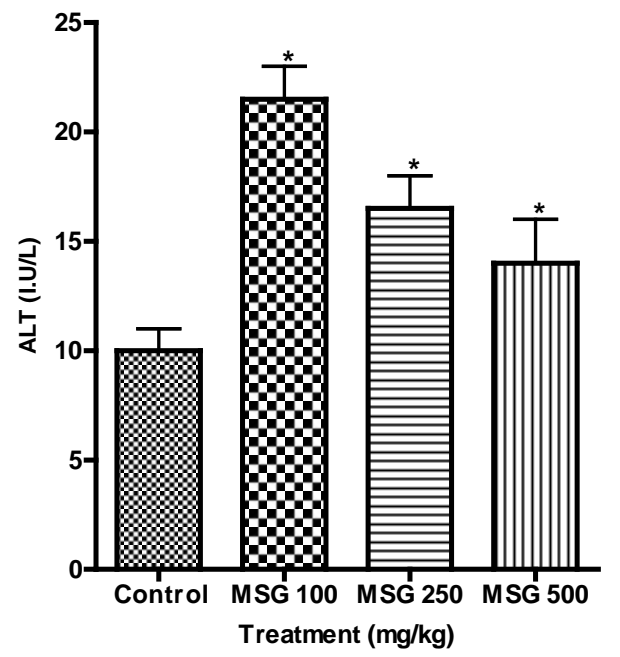

(b)

Figure 4. Effects of monosodium glutamate on aspartate aminotransferase (a) and alanine aminotransferase (b) activities in the blood. Columns represent the Mean \pm S.E.M for 5 animals per group. ${ }^{*} P<0.05$ compared with control group.

Table 3. Effects of monosodium glutamate on the brain levels of malondialdehyde and glutathione in mice.

\begin{tabular}{cccc}
\hline Treatment Group & Dose $(\mathrm{mg} / \mathrm{kg})$ & GSH $(\mu \mathrm{mol} / \mathrm{g}$ tissue $)$ & MDA $(\mu \mathrm{mol} / \mathrm{g}$ tissue $)$ \\
\hline Control & - & $26.88 \pm 1.44$ & $60.06 \pm 4.52$ \\
MSG & 100 & $24.38 \pm 1.17$ & $66.54 \pm 4.11$ \\
MSG & 250 & $20.04 \pm 1.34^{*}$ & $78.03 \pm 3.82^{*}$ \\
MSG & 500 & $18.50 \pm 1.46^{*}$ & $86.97 \pm 3.81^{*}$ \\
\hline
\end{tabular}

Values represent the Mean \pm S.E.M for 5 animals per group. ${ }^{*} P<0.05$ versus control. 


\section{Discussion}

The results of this study showed that oral administration of $100-500 \mathrm{mg} / \mathrm{kg}$ of MSG daily for 21 days did not significantly alter the patterns of alternation behaviors of mice in the Y-maze test. The Y-maze test is a recognized animal model routinely used for the evaluation of memory performance in rodents. This test is based on the ability of rodents to remember the sequence of arms entry, commonly known as spontaneous alternations [25]. The list of arms visited is believed to be held in spatial working memory, thus serving as a measure of short-term memory [26]. Previous preclinical studies have shown that intraperitoneal or subcutaneous injection of MSG or given with animal foods at doses $4-8 \mathrm{~g} / \mathrm{kg}$ produced neuronal degeneration resulting in loss of memory [5] [8]-[19]. However, Hashem et al., [27] reported that $3 \mathrm{~g} / \mathrm{kg} /$ day of MSG mixed with rat foods for 14 days produced degenerative changes in the cerebral cortex of the brain region. The dosages of MSG used in these studies were very high and the methods of administration, as well as force feeding, did not accurately represent the way humans consume MSG [2] [11]. High oral doses of MSG have been reported to be well tolerated by humans as well as adult gerbils as it did not produce any neurological changes [4] [12]. These findings further confirm that the neurotoxic effects of MSG are determined mainly by the quantity administered and the route of administration. The lowest dose used in most studies was $2 \mathrm{~g} / \mathrm{kg}$ of body weight, which corresponded to an ingestion of $140 \mathrm{~g}$ in a $70 \mathrm{~kg}$ man, while the average daily intake of MSG had been estimated to be $0.3-1.0 \mathrm{~g}$ [4]. Thus, further animal studies involving the effects of MSG on the brain should be done by using doses similar to human intake. In addition, oral route should be considered for further studies, since MSG is known to be completely metabolized by the liver with evidence of high first pass effect [2] [12] [28]. Another key factor influencing MSG-induced neurotoxicity is the age of the animals and the deleterious effects of MSG are commonly reported in neonatal brains [2]. This has been attributed to the fact that MSG did not readily cross the blood brain barrier to exert its neurotoxic effects in adult brains [2]. Thus, future extrapolation of animal data to human settings should be done with considerations of these vital issues; relating to doses, route of administration and age of the animals.

The effect of MSG on animal behavior was further evaluated in this study using EPM and light/dark transition tests in mice. The EPM and light/dark transition tests are animal models widely used for evaluation of agents with anxiolytic or anxiogenic property [22]. The behavioral changes seen in EPM and light/dark transition tests are due to the natural aversion of rodents for open and light environments. Thus, the measures of anxiety in the EPM test are based on the alterations in the number of open arm entries and the total time spent in the open arm arena [22]. Whereas, the increase in duration of time spent in the dark compartment of the light/dark box indicates a state of anxiety in rodents [22] [29]. However, oral administration of $100-500 \mathrm{mg} / \mathrm{kg}$ MSG did not significantly alter the behavioral performance of mice in the EPM and light/dark transition tests. This finding further supports the notion that MSG given orally in doses that correspond to its average dietary intake is well tolerated by animals and humans [12]. On the other hand, there are reports in literature, which showed that MSG produced anxiogenic effect through stimulation of sympathetic nervous system [5]. However, these studies used parenteral routes or forced feeding and high doses (4 - $8 \mathrm{~g} / \mathrm{kg}$ ) of MSG, which tended to compromise the clinical implications of these findings. In addition, the hyperlocomotion seen in rodents treated with high doses of MSG may have also resulted from increased sympathetic discharges or activation of glutamate receptors [30]. However, the results of our study showed that MSG did not significantly modify SMA, which further suggested that its neurotoxic effect was determined by the quantity taken. The tendency of MSG to induce behavioral depression was also assessed using FST. The FST induces depressive-like symptoms in rodents that resemble endogenous depression in humans [21] [31]. The parameters measured in this test include the first occurrence of immobility, duration of immobility and total time spent in active swimming. The first occurrence of immobility signals the onset of hopelessness or despair while prolonged duration of immobility reflects a state of behavioral depression [21] [30]. In this study, oral administration of MSG at $500 \mathrm{mg} / \mathrm{kg}$ but not at lower doses induced depressive-like symptoms in the FST in mice but this finding needs further investigations.

The biochemical assays carried out in this study showed that MSG (250 and $500 \mathrm{mg} / \mathrm{kg}$ ) produced significant elevation of MDA levels accompanied by depletion of GSH concentrations in mouse brain, which suggested increased oxidative stress. Oxidative stress occurs when reactive oxygen species (ROS) accumulate in cells, either from excessive production or insufficient degradation, resulting in cellular damage [32]. Previous preclinical studies have shown that MSG at various doses induces oxidative stress in many organs of the body and also damages liver cells [1] [13]. Increased reactive oxygen species (ROS) had been implicated in the massive neu- 
ronal cell destructions associated with prolonged and high doses of MSG [33]. Perhaps, oxidative stress may be playing a vital role in MSG-induced neurodegeneration in discrete brain regions in early postnatal mice [34]. Thus, memory impairment linked with high doses of MSG may be mediated through oxidative stress. Indeed, several studies had implicated oxidative stress in the pathology of Alzheimer disease, a neurodegenerative disorder associated with memory loss [35] [36]. However, results of our studies indicate that MSG did not impair memory in Y-maze paradigm. This finding suggests that the degree of lipid perioxidative tissue damage might not have been severe enough to compromise memory function and other behavioral phenotypes. MSG also elevated the serum ALT and AST levels, which were routinely used as biomarkers of liver injury [15]. Thus, increase in serum ALT and AST levels might perhaps be an indication of liver damage in MSG-treated animals. MSG is known to dissociate to glutamate, which in turns produces ammonium ions that cause toxicity to the liver [3]. The ammonium ion overload that occurs as a result of increased level of glutamate following MSG intake damages the liver and thus, the release of ALT and AST enzymes [3]. Ammonium ion overloads also trigger the formation of reactive oxygen species, which react with polyunsaturated fatty acids of cell membrane leading to impairment of mitochondrial and plasma membranes accompanied by leakage of liver enzymes such as ALT and AST [14]. Tawfik \& Al-Badr [3] also showed that MSG impaired liver function and elevated serum ALT and AST levels in rat at doses lower than those used in this study. Although impaired liver function may result in increased blood level of MSG, the implications of such finding on brain functions need further investigations.

\section{Conclusion}

The results of this study suggested that MSG induced oxidative stress in mouse brain and elevated serum liver function enzymes but did not produce significant behavioral abnormalities at lower doses in mice.

\section{Acknowledgements}

We specially appreciate various contributions received from members of the Neuropharmacology Unit of the Department of Pharmacology and Therapeutics, University of Ibadan, Ibadan.

\section{Conflict of Interest}

Authors declare that there is no conflict of interest.

\section{References}

[1] Eweka, A.O., Igbigbi, P.S. and Ucheya, R.E. (2011) Histochemical Studies of the Effects of Monosodium Glutamate on the Liver of Adult Wistar Rats. Annals of Medical \& Health Sciences Research, 1, 21-29.

[2] Husarova, V. and Ostatnikov, D. (2013) Monosodium Glutamate Toxic Effects and Their Implications for Human Intake: A Review. JMED Research, Article ID: 608765. http://dx.doi.org/10.5171/2013.608765

[3] Tawfik, M.S. and Al-Badr, N. (2012) Adverse Effects of Monosodium Glutamate on Liver and Kidney Functions in Adult Rats and Potential Protective Effect of Vitamins C and E. Food and Nutrition Sciences, 3, 651-659. http://dx.doi.org/10.4236/fns.2012.35089

[4] Geha, R.S., Beiser, A., Ren, C., Patterson, R., Greenberger, P.A., Grammer, L.C., Ditto, A.M., Harris, K.E., Shaughnessy, M.A., Yarnold, P.R., Corren, J. and Saxon, A. (2000) Review of Alleged Reaction to Monosodium Glutamate and Outcome of a Multicenter Double-Blind Placebo-Controlled Study. Journal of Nutrition, 130, 1058S-1062S.

[5] Samuels, A. (1999) The Toxicity/Safety of MSG: A Study in Suppression of Information. Accountability in Research: Policies and Quality Assurance, 6, 259-310. http://dx.doi.org/10.1080/08989629908573933

[6] Meldrum, B. (1993) Amino Acids as Dietary Excitotoxins: A Contribution to Understanding Neurodegenerative Disorders. Brain Research Reviews, 18, 293-314. http://dx.doi.org/10.1016/0165-0173(93)90014-Q

[7] Olney, J.W. (1969) Brain Lesions, Obesity and Other Disturbances in Mice Treated with Monosodium Glutamate. Science, 164, 719-721. http://dx.doi.org/10.1126/science.164.3880.719

[8] Beas-Zarate, C., Schliebs, R., Morales-Villagran, A. and Feria-Velasco, A. (1989) Monosodium L-Glutamate-Induced Convulsions: Changes in Uptake and Release of Catecholamines in Cerebral Cortex and Caudate Nucleus of Adult Rats. Epilepsy Research, 4, 20-27. http://dx.doi.org/10.1016/0920-1211(89)90054-5

[9] Pelaez, B., Blazquez, J.L., Pastor, F.E., Sanchez, A. and Amat, P. (1999) Lectin Histochemistry and Ultrastructure of Microglial Response to Monosodium Glutamate-Mediated Neurotoxicity in the Arcuate Nucleus. Histology and Histopathology, 14, 165-174. 
[10] Arauz-Contreras, J. and Feria-Velasco, A. (1984) Monosodium-L-Glutamate-Induced Convulsions-I. Differences in Seizure Pattern and Duration of Effect as a Function of Age in Rats. General Pharmacology, 15, 391-395. http://dx.doi.org/10.1016/0306-3623(84)90036-3

[11] Rivera-Cervantes, M.C., Torres, J.S., Feria-Velasco, A., Armendariz-Borunda, J. and Beas-Zarate, C. (2004) NMDA and AMPA Receptor Expression and Cortical Neuronal Death Are Associated with p38 in Glutamate-Induced Excitotoxicity in Vivo. Journal of Neuroscience Research, 76, 678-687. http://dx.doi.org/10.1002/jnr.20103

[12] Reeds, P.J., Burrin, D.G., Jahoor, F., Wykes, L., Henry, J. and Frazer, E.M. (1996) Enteral Glutamate Is Almost Completely Metabolized in First Pass by the Gastrointestinal Tract of Infant Pigs. American Journal of Physiology, 270, E413-E418.

[13] Onyema, O.O., Farombi, E.O., Emerole, G.O., Ukoha, A.I. and Onyeze, G.O. (2006) Effect of Vitamin E on Monosodium Glutamate Induced Hepatotoxicity and Oxidative Stress in Rats. Indian Journal of Biochemistry \& Biophysics, 43, 20-24.

[14] Poli, G., Albano, E. and Dianzani, M.U. (1990) Lipid Peroxidation and Covalent Binding in the Early Functional Impairment of Liver Golgi Apparatus by Carbon Tetrachloride. Cell Biochemistry and Function, 8, 1-10. http://dx.doi.org/10.1002/cbf.290080102

[15] Giffen, P.S., Pick, C.R., Price, M.A., Williams, A. and York, M.J. (2002) Alpha-Glutathione S-Transferase in the Assessment of Hepatotoxicity - Its Diagnostic Utility in Comparison with Other Recognized Markers in the Wistar Han Rat. Toxicologic Pathology, 30, 365-372. http://dx.doi.org/10.1080/01926230252929945

[16] Rhodes, J., Titherley, A.C., Norman, J.A., Wood, R. and Lord, D.W. (1991) A Survey of the Monosodium Glutamate Content of Foods and an Estimation of the Dietary Intake of Monosodium Glutamate. Food Additives \& Contaminants, 8, 663-672. http://dx.doi.org/10.1080/02652039109374021

[17] Casadesus, G., Webber, K.M., Atwood, C.S., Pappolla, M.A., Perry, G., Bowen, R.I. and Smith, M.A. (2006) Luteinizing Hormone Modulates Cognition and Amyloid-Beta Deposition in Alzheimer APP Transgenic Mice. Biochimica Biophysica Acta, 1762, 447-452. http://dx.doi.org/10.1016/j.bbadis.2006.01.008

[18] Pellow, S., Chopin, P., File, S.E. and Briely, B. (1985) Validation of Open-Closed Arm Entries in Elevated plus Maze as a Measure of Anxiety in the Rat. Journal of Neuroscience Methods, 14, 149-167. http://dx.doi.org/10.1016/0165-0270(85)90031-7

[19] Bourin, M., Petit-Demouliere, B., Donnchadha, B.N. and Hascoet, M. (2007) Animal Models of Anxiety in Mice. Fundamental \& Clinical Pharmacology, 21, 567-571. http://dx.doi.org/10.1111/j.1472-8206.2007.00526.x

[20] Walsh, R.N. and Cummins, R.A. (1976) The Open Field Test: A Critical Review. Psychological Bulletin, 83, $482-504$. http://dx.doi.org/10.1037/0033-2909.83.3.482

[21] Porsolt, R.D., Anton, G., Deniel, M. and Jalfre, M. (1978) Behavioural Despair in Rats: A New Animal Model Sensitive to Antidepressant Treatments. European Journal of Pharmacology, 47, 379-391. http://dx.doi.org/10.1016/0014-2999(78)90118-8

[22] Moron, M.S., Depierre, J.W. and Mannervik, B. (1979) Levels of Glutathione, Glutathione Reductase and Glutathione S-Transferase Activities in Rat Lung and Liver. Biochimica et Biophysica Acta, 582, 67-78. http://dx.doi.org/10.1016/0304-4165(79)90289-7

[23] Adam-Vizi, V. and Seregi, A. (1982) Receptor Independent Stimulatory Effect of Noradrenaline on $\mathrm{Na}^{+} / \mathrm{K}^{+}-\mathrm{ATPase}$ in Rat Brain Homogenate. Role of Lipid Peroxidation. Biochemical Pharmacology, 34, 2231-2236. http://dx.doi.org/10.1016/0006-2952(82)90106-X

[24] Steven, C.K. (1996) Alanine and Aspartate Aminotransferase, Principle and Usage. In: James, J.T. and Jenifer, R., Eds., Liver Function, in Clinical Chemistry Theory, Analysis and Correlation, 3rd Edition, M. Mosby, London, 504-527.

[25] Blokland, A. (2005) Scopolamine-Induced Deficits in Cognitive Performance: A Review of Animal Studies. Scopolamine Review, 1, 1-76.

[26] Lee, M., Yun, B., Zhang, D., Liu, L., Wang, Z., Wang, C., Gu, L., Wang, C., Mo, E., Ly, S. and Sung, C. (2010) Effect of Aqueous Antler Extract on Scopolamine Induced Memory Impairment in Mice and Antioxidant Activities. Food Science and Biotechnology, 19, 655-661. http://dx.doi.org/10.1007/s10068-010-0092-0

[27] Hashem, H.E., El-Din Safwat, M.D. and Algaidi, S. (2012) The Effect of Monosodium Glutamate on the Cerebellar Cortex of Male Albino Rats and the Protective Role of Vitamin C (Histological and Immunohistochemical Study). Journal of Molecular Histology, 43, 179-186. http://dx.doi.org/10.1007/s10735-011-9380-0

[28] Bazzano, G., D’Elia, J.A. and Olson, R.E. (1970) Monosodium Glutamate: Feeding of Large Amounts Glutamate. Science, 169, 1208-1209. http://dx.doi.org/10.1126/science.169.3951.1208

[29] Crawley, J. and Goodwin, F.K. (1980) Preliminary Report of a Simple Animal Behavior Model for the Anxiolytic Effects of Benzodiazepines. Pharmacology Biochemistry and Behavior, 13, 167-170. http://dx.doi.org/10.1016/0091-3057(80)90067-2 
[30] Ali, M.M., Bawari, M., Misra, U.K. and Babu, G.N. (2000) Locomotor and Learning Deficits in Adult Rats Exposed to Monosodium-L-Glutamate during Early Life. Neuroscience Letters, 284, 57-60. http://dx.doi.org/10.1016/S0304-3940(00)00958-7

[31] Nagaraja, H.S. and Jeganathan, P.S. (1999) Forced Swimming Stress Induced Changes in the Physiological and Biochemical Parameters in Albino Rats. Indian Journal of Physiology and Pharmacology, 43, 53-59.

[32] Natalie, A.I., Kelsey, M., Heather, I., Wilkins, D.A. and Linseman, D. (2010) Nutraceutical Antioxidants as Novel Neuroprotective Agents. Molecules, 15, 7792-7814. http://dx.doi.org/10.3390/molecules15117792

[33] Farombi, E.O. and Onyema, O.O. (2006) Monosodium Glutamate Induced Oxidative Damage and Genotoxicity in the Rat: Modulatory Role of Vitamin C, Vitamin E and Quercetin. Human Experimental Toxicology, 25, 251-259. http://dx.doi.org/10.1191/0960327106ht621oa

[34] Hu, L., Fernstrom, J.D. and Goldsmith, P.C. (1998) Exogenous Glutamate Enhances Glutamate Receptor Subunit Expression during Selective Neuronal Injury in the Ventral Arcuate Nucleus of Postnatal Mice. Neuroendocrinology, 68, 77-88. http://dx.doi.org/10.1159/000054353

[35] Markesbery, W.R. (1997) Oxidative Stress Hypothesis in Alzheimer’s Disease. Free Radical Biology and Medicine, 23, 134-147. http://dx.doi.org/10.1016/S0891-5849(96)00629-6

[36] Tabet, N., Mantle, D. and Orrell, M. (2000) Free Radicals as Mediators of Toxicity in Alzheimer's Disease: A Review and Hypothesis. Adverse Drug Reactions and Toxicology Reviews, 19, 127-152. 